\title{
Publisher Correction: A multi-ethnic epigenome- wide association study of leukocyte DNA methylation and blood lipids
}

Min-A Jhun (1), Michael Mendelson (1), Rory Wilson (1), Rahul Gondalia, Roby Joehanes (D), Elias Salfati, Xiaoping Zhao, Kim Valeska Emilie Braun (1), Anh Nguyet Do, Åsa K. Hedman (1), Tao Zhang, Elena CarneroMontoro (D, Jincheng Shen, Traci M. Bartz, Jennifer A. Brody (1), May E. Montasser, Jeff R. O'Connell, Chen Yao (D), Rui Xia, Eric Boerwinkle, Megan Grove, Weihua Guan, Pfeiffer Liliane, Paula Singmann (D), Martina Müller-Nurasyid (D), Thomas Meitinger, Christian Gieger, Annette Peters (D), Wei Zhao (D), Erin B. Ware (D), Jennifer A. Smith (D), Klodian Dhana, Joyce van Meurs, Andre Uitterlinden (1), Mohammad Arfan Ikram (D), Mohsen Ghanbari(D), Deugi Zhi, Stefan Gustafsson (D), Lars Lind, Shengxu Li, Dianjianyi Sun, Tim D. Spector (D), Yii-der Ida Chen, Coleen Damcott (1), Alan R. Shuldiner, Devin M. Absher, Steve Horvath (1), Philip S. Tsao (1D, Sharon Kardia, Bruce M. Psaty, Nona Sotoodehnia, Jordana T. Bell D, Erik Ingelsson, Wei Chen (1), Abbas Dehghan, Donna K. Arnett (B), Melanie Waldenberger (1), Lifang Hou, Eric A. Whitsel, Andrea Baccarelli, Daniel Levy, Myriam Fornage (10), Marguerite R. Irvin \& Themistocles L. Assimes (1)

Correction to: Nature Communications https://doi.org/10.1038/s41467-021-23899-y, published online 28 June 2021.

The original version of this Article contained an error in the spelling of the author Min-A Jhun which was incorrectly given as Mina-A Jhun. This has now been corrected in both the PDF and HTML versions of the Article.

Published online: 06 July 2021

\footnotetext{
reproduction in any medium or format, as long as you give appropriate credit to the original author(s) and the source, provide a link to the Creative Commons license, and indicate if changes were made. The images or other third party material in this article are included in the article's Creative Commons license, unless indicated otherwise in a credit line to the material. If material is not included in the article's Creative Commons license and your intended use is not permitted by statutory regulation or exceeds the permitted use, you will need to obtain permission directly from the copyright holder. To view a copy of this license, visit http://creativecommons.org/licenses/by/4.0/.
} 